Open Access

\title{
Chinese employees' leadership preferences and the relationship with power distance orientation and core self-evaluation
}

\author{
Cai-Hui Veronica Lin ${ }^{1}$ and Jian-Min James Sun ${ }^{2^{*}}$
}

\author{
* Correspondence: \\ chinajms@126.com \\ ${ }^{2}$ School of Labor and Human \\ Resources, Renmin University of \\ China, Beijing, China \\ Full list of author information is \\ available at the end of the article
}

\begin{abstract}
Informed by implicit leadership theories, this study investigates contemporary Chinese employees' preferences for paternalistic leadership (including three components: moral leadership, benevolent leadership and authoritarian leadership) and transformational leadership. It further examines the relationship between power distance orientation, core self-evaluation (CSE) and leadership preferences. The study finds that contemporary Chinese employees most prefer moral leadership, but are also highly receptive to transformational leadership. They prefer authoritarian leadership least. Moreover, preferences for authoritarian leadership are predicated on followers' power distance orientation. However, the opposite is true for moral leadership. CSE is positively related to followers' preference for authoritarian leadership, benevolent leadership and transformational leadership, but not except for moral leadership. A positive interaction effect is found between power distance orientation and CSE with regard to authoritarian leadership preference. The theoretical and practical implications of the findings are discussed.
\end{abstract}

Keywords: Contemporary Chinese employees, Leadership preference, Power distance orientation, Core self-evaluation (CES)

\section{Introduction}

Early leadership literature emphasizes the primary importance of leaders and concentrates on the impact of a leader's traits, behaviors and influencing tactics on followers' attitudes and behaviors (e.g., Yukl 1998). In the past few years, a small but active stream of research with a focus on followers has emerged (Dvir and Shamir 2003; Foti et al. 2017; Howell and Shamir 2005; Junker and van Dick 2014; Shamir et al. 2007; Thoroughgood and Sawyer 2018). Researchers endorsing this follower-centric perspective assert that followers are not passive recipients of leader's behaviors. Rather, they are active co-producers of leadership relationships and effectiveness. In the leadership process, followers largely determine the type of leadership that is formed and exert influence on leadership effectiveness (Epitropaki and Martin 2005; Howell and Shamir 2005; Rogiest et al. 2018; Shamir et al. 2007; Shin and Zhou 2003).

Implicit leadership theories (Alipour et al. 2017; Eden and Leviatan 1975; Junker and van Dick 2014; Lord and Smith 1983) suggest that the starting point to understanding leadership from the perspective of followers is to understand their leadership preferences,

(c) The Author(s). 2018 Open Access This article is distributed under the terms of the Creative Commons Attribution 4.0 International License (http://creativecommons.org/licenses/by/4.0/), which permits unrestricted use, distribution, and reproduction in any medium, provided you give appropriate credit to the original author(s) and the source, provide a link to the Creative Commons license, and indicate if changes were made. 
which represent followers' beliefs and expectations of what an ideal leader should be like. Followers evaluate a potential leader's behaviors and compare them with their preferred leadership behaviors. The more fit they find between the potential leader's behaviors and their preferred leadership behaviors, the more likely they will recognize the potential leader as a real leader (Budin and Wafa 2015; Foti and Luch 1992; Ling et al. 2000). Closeness between an actual superior's leadership style and the employee's ideal one has significant implications. It is associated with a good leader-follower relationship, high employee organizational commitment, job satisfaction, and well-being (Chia et al. 2015; Epitropaki and Martin 2005; Subramaniam et al. 2010), whereas discrepancies between actual and preferred leadership result in lower employee satisfaction (Vecchio and Sussman 1989). Given the importance of fit between a follower's ideal and preferred leadership behaviors, it is imperative for leaders to clearly understand followers' leadership preferences. However, there has been little systematic research to date about employees' leadership style preferences, especially in emerging economies such as China.

In Chinese society, eastern and western management practices coexist (Warner 2004). The same observation applies to leadership. On the one hand, traditional paternalistic leadership is still prevalent in Chinese business organizations (Cheng et al. 2004; Cheng et al. 2000; Li and Sun 2015). On the other hand, transformational leadership, which is actively advocated by western scholars and is considered the most effective leadership style (Bass 1990; Bass and Riggio 2006; Conger and Kanungo 1998), is also found in China (e.g., Li et al. 2015; Li and Shi 2008; Sun et al. 2014; Wang et al. 2005). Knowledge about Chinese employees' preference for these two leadership styles will help both domestic and international managers to quickly identify the leadership style that is most effective for Chinese employees and help them choose between "transplanting" and "localizing" their leadership styles. Theoretically, it will also provide a more comprehensive perspective in leadership and followership research as well as cross-cultural study.

Further, the existing research does not sufficiently examine what factors might explain an individual's leadership preferences. Inquiry into this question will not only address the foundation of leadership preference in theory, but also help leaders to "customize" their behaviors for each follower. As the workplace in China is becoming increasingly diversified (Sheldon et al. 2011; Cooke 2011), individualized leader efforts might be most successful (Dansereau et al. 1995). In this study, we focus on individuals' power distance orientation and core self-evaluation (CSE) as two potential factors explaining individual leadership preference. Power is inherent to leadership. Whether one accepts the power inequality in society and institutions (i.e., power distance orientation) is crucial in conceptualizing the leadership relationship (Kirkman et al. 2009). Additionally, it is acknowledged that self-concept predicts leadership prototypes. People tend to endorse leadership characteristics which they believe are positive and they themselves possess (Foti et al. 2012; McElwee et al. 2001). CSE has been widely studied as a broad personality construct and regarded as a good predictor for attitude and behavior in the workplace (Judge 2009; Judge et al. 2002; Judge et al. 1997; Rode et al. 2012) as well as being related to leadership ratings (Hu et al. 2012). Hence, power distance orientation and CSE potentially shape an individual's leadership preferences.

The rest of the paper is organized in the following way. First, we introduce the theoretical background and hypotheses. Then we compare Chinese employees' overall level of preference for paternalistic leadership and transformational leadership. Third, we investigate the 
association between followers' power distance orientation, CSE and their preference for each leadership style and present the results. We conclude with a discussion on the implication of the findings for managers both within the Chinese context and beyond.

\section{Theory and hypotheses}

Implicit leadership theories

Implicit leadership theories postulate that people have implicit benchmarks (i.e., prototypes) of what constitutes a good leader (Eden and Leviatan 1975). They compare a potential leader with the prototypes and act according to the outcome of the comparisons (Lord et al. 1984). When there is high congruence between the potential leader and the implicit leader, leadership will be recognized. A number of factors shape implicit leadership prototypes, such as macro-level cultural characteristics, organizational context and micro level follower characteristics (Junker and van Dick 2014). As a consequence, individuals' leadership preferences have both shared and idiosyncratic components. Below we explain what Chinese employees' overall level of leadership preference is with reference to paternalistic and transformational leadership within the Chinese context. Following that, we explain the foundations of each leadership preference, that is, how followers' power distance orientation and CSE relate to their preferences for each leadership style.

\section{Paternalistic and transformational leadership}

Paternalistic leadership is characterized by a combination of strong discipline and authority, fatherly benevolence and moral integrity (Cheng et al. 2004; Farh and Cheng 2000). It comprises three elements: authoritarianism, benevolence and morality. Authoritarianism is manifested by leader's behaviors such as accentuation of authority and control, underestimation of follower competence, image-building behaviors and didactic behaviors. Benevolence is characterized by individualized care of followers, such as treating followers as family members, showing holistic concern for followers and protecting followers from embarrassment. Leader morality entails two major virtues: unselfishness and leading by example (Farh and Cheng 2000). Although some researchers argue that these three elements coexist and characterize paternalistic leadership as a whole (Wu et al. 2012), Cheng (1995) finds that authoritarianism and benevolence can hardly be employed simultaneously by one leader. Usually they are displayed by two leaders who take on two different roles. Farh and Cheng (2000) further recommend conceptualizing the three elements as three leadership styles. Similarly, Aycan (2006) concurs that paternalistic leadership is not a unified construct. Following their suggestions we treat the three elements as three leadership styles under the broad umbrella term of paternalistic leadership.

Transformational leadership, which is used interchangeably with "charismatic leadership", "visionary leadership" and "inspirational leadership", refers to a leadership style that appeals to followers' values, activates followers' high-order needs and moves them to transcend their self-interest for the sake of the organization (Bass 1985; Bass and Riggio 2006; Yukl 1998). Transformational leaders can be distinguished from non-transformational leaders by their sensitivity to environmental contexts, including followers' needs and abilities, the idealized nature of their goals and the way they articulate these goals, and the trust they 
build in followers through personal example and risk-taking behaviors (Conger and Kanungo 1998).

Although there are a few studies comparing followers' preference for either transformational or transactional leadership (Brain and Lewis 2004; Fein et al. 2010; Singer and Singer 2001), or between charismatic leadership, or relationship-oriented and task-oriented leadership (Ehrhart and Klein 2001), to our knowledge, there is no study comparing followers' preference for paternalistic and transformational leadership. However, the growing number of western organizations which seek to expand their business horizons globally, and the prevalence of paternalistic leadership in many regions such as Asia Pacific, the Middle East, and Latin America (Aycan 2006; Pelligrini and Scandura 2008) make this a legitimate inquiry.

\section{Chinese employees' leadership preferences}

Among the three elements of paternalistic leadership, moral leadership is characterized by leaders' superior personal virtues or qualities. In the Chinese context, two virtues are particularly prominent: unselfishness and leading by example (Farh and Cheng 2000). Chinese people expect leaders to refrain from abusing power and to serve as an exemplar for followers. This expectation originates both from the Confucian tradition and from employees' need for their own well-being (Cheng et al. 2004). Confucianism advocates the use of moral principles and moral examples, arguing that law and punishment can only regulate overt behaviors, whereas moral persuasion can govern inner thought. Moreover, in Chinese organizations the phenomena of "rule by man" and nepotism still widely exist despite the development of legal institutions (Dunfee and Warren 2001). As a result, followers have to count on leaders' personal virtue to avoid being disadvantaged (Cheng et al. 2004). Thus, Confucian ideology and social reality lead to strong preferences from Chinese employees for honest and upright leaders. In Ling et al.'s (2000) study on Chinese implicit leadership theories, a leader's personal morality is regarded as a factor that is distinct from western examples. It explains the most variance in the ideal leaders' traits for Chinese people.

Benevolent leadership refers to behaviors that demonstrate personal favors and generosity (Farh and Cheng 2000). In China it covers the domain of both work and personal life. In the work domain, benevolent leaders allow followers opportunities to correct their mistakes, avoid publicly embarrassing them, provide them with coaching, and be concerned with their career development. In the non-work family domain, benevolent leaders treat followers as family members and create the atmosphere of a big family. They assist followers during their personal crises, and show holistic concern for them (Farh et al. 2008). Confucianism defines the role obligations of superiors and inferiors, according to which superiors should treat inferiors with kindness and benevolence, while inferiors reciprocate with deference, loyalty and obedience. However, in Chinese families, an affectionate father is not very common (Ho 1987), possibly because benevolence undermines authority and the two are difficult to reconcile in one person (Cheng 1995). When the image of a less benevolent father is "transferred" to the workplace (Bing 2004; Pelligrini and Scandura 2006), we expect that benevolence is less likely to characterize the ideal leader for Chinese employees than morality. 
Authoritarian leadership emphasizes a leader's personal authority and dominance over followers. Authoritarian leaders have centralized power and assume a father-like role. They adopt top-down communication styles and are unwilling to be delegated. They keep their intentions ill-defined, implement manipulation tactics and are concerned with projecting a powerful image of themselves (Silin 1976). These behaviors invoke fear and awe on the part of followers (Farh and Cheng 2000; Farh et al. 2006). Although once often observed in Chinese organizations, there is evidence that more recently authoritarian leadership is becoming less popular. A number of recent studies demonstrate that leader authoritarianism results in negative employee outcomes (Cheng, Huang, \& Chou 2002; Farh et al. 2006; Li and Sun 2015; Wu et al. 2012) partly due to followers' perception of abusiveness and injustice which undermine trust in their leaders (Wu et al. 2012) while both trust and reciprocity have been empirically demonstrated as mediators in the relationship between leadership and employee attitudes (Jia et al. 2007).

The cross-culture GLOBE program finds that leader's attributes such as charisma, being inspirational, and being visionary are universally endorsed (Den Hartog et al. 1999). In particular, similar to moral leadership, transformational leadership speaks to followers' moral needs. It raises followers to higher levels of morality and to "more principled levels of judgement" (Burns 1978, p.455) and transcends followers' own interests for the sake of collective interests. A crucial aspect of transformational leadership is role-modeling a contribution to the collective (Bass 1985; Burns 1978; Yaffe and Kark 2011). Such leadingby-example behaviors are also an important component of moral leadership. Research on transformational leadership in China reveals that it results in positive responses from Chinese employees, such as identification, job satisfaction, organizational commitment (Cheng et al. 2004; Walumba et al. 2004) and voluntary citizenship behaviors (Wang et al. 2005). One study (Wu et al. 2007) notes that the effect of transformational leadership even goes beyond that of moral and benevolent leadership. Hence, we expect that Chinese preference for transformational leadership will be similar to their preference for moral leadership. We hypothesize:

H1: Chinese employees prefer moral and transformational leadership most, followed by benevolent leadership. Authoritarian leadership is least preferred by Chinese employees.

\section{Follower power distance orientation and leadership preferences}

Power distance is originally identified as a dimension for analyzing national culture (Hofstede 1997). It informs the dependent relationship between followers and leaders. Later on, scholars propose individual power distance orientation as a variable at the individual level and demonstrate its impact on leadership perception and effectiveness (Eylon and Au 1999; Kirkman et al. 2009) An individual's value orientation shapes his/ her cognition about what behaviors, skills and personality characterize an effective leader (Ehrhart and Klein 2001; Keller 2006; Kirkman et al. 2009). Power distance orientation concerns an individual's beliefs about status, authority and power distribution in organizations. Individuals with a high power distance orientation are mentally dependent on their leaders. Inequalities between supervisors and subordinates are expected and accepted. They rely on leaders' one-way directives with little explanation or 
clarification, defer to leaders' instructions and are unlikely to question leaders (Kirkman et al. 2009). In contrast, individuals with a lower power distance orientation may value their supervisors less and thus be less likely to develop strong tendencies to depend upon their supervisors.

Farh and Cheng (2000) point out that the legitimacy of authoritarian leadership in China originates from the family relationships that are regulated by Confucianism. According to Confucianism, in a family, the grandfather or father has absolute authority over other family members and all the family members should obey him. This patriarchalism in the family then generalizes to other social organizations such as companies where the leaders / managers take on the role of father and employees the role of children. Redding (1990) states that authoritarian leadership would not work unless the followers respect authority and have a dependent mind-set.

The dependent mind-set inherent to power distance orientation is also related to one's longing for care from authority figures. It has been observed that in high power distance families, senior members will take care of the juniors even after they are able to live independently (Hofstede 1997). When this relationship is generalized to organizations, individuals will develop a preference for benevolent leadership. Therefore, we argue that the expectation of leader benevolence in fact reflects an individual's psychological dependence on the leader.

Based on these arguments, we hypothesize that:

H2: Followers' power distance orientation is positively related with their preference for authoritarian leadership.

H3: Followers' power distance orientation is positively related with their preference for benevolent leadership.

Followers' preference for leader morality arises from Confucian ideology and power asymmetry in Chinese society. According to Confucian ideology, a person only deserves to be regarded as a leader when he/she is morally superior to his/her followers. The recognition of leaders' moral superiority and the acceptance of morally superior persons in a leadership position and the exercise of power per se, we argue, is a manifestation of high power distance orientation. In addition, incomplete legal systems and institutions in society and organizations force followers to rely on a leader's personal morality to protect them from being disadvantaged. Thus, to the extent that a follower accepts power asymmetry in society and institutions, he/she would rely on leader morality and prefer moral leadership. Therefore, we hypothesize:

H4: Followers' power distance orientation is positively related with their preference for moral leadership.

As far as transformational leadership is concerned, the relationship is less clear. Transformational leadership paradoxically has two faces: empowerment and dependency (Kark et al. 2003). On the one hand, transformational leaders are empowering. They highlight the importance of an assignment and instill inspirational motivation into followers. They point to the challenges involved and the exciting achievement to be 
brought by success (Bass and Riggio 2006). These behaviors lead to follower's growth, independence and empowerment (Bass and Steidlmeier 1999; Dvir et al. 2002). On the other hand, transformational leadership has the potential to weaken the abilities of followers and increase their dependency on their leader's recognition and approval (Conger and Kanungo 1998; Yukl 1998). Followers might perceive the leader as a superhuman and depend on him / her for guidance and inspiration.

Although Katz and Kahn (1978) believe that transformational leadership entails a large distance between followers and leaders, because distance allows followers to "build an aura of magic" (p. 546) and makes the emergence of charisma possible, other scholars argue that with either large or small social distance charisma can be ascribed to leaders (Antonakis and Atwarter 2002; Bass 1990; Shamir 1995). Socially distant leaders are ascribed charisma by exceptional organizational performance, visionary behavior, use of rhetoric, etc. In contrast, socially close leaders can be described as transformational by setting personal examples (Shamir 1995). They operate differently, but both can be ascribed charisma. As power distance is a similar construct as social distance (Antonakis and Atwarter 2002), these arguments suggest that the emergence of transformational leadership can be independent from power distance. This might also explain why the various elements of transformational leadership are universally held as the ideal attributes of a leader (Den Hartog et al. 1999). As such, no hypothesis is formulated with regard to the relationship between power distance orientation and transformational leadership preference.

\section{Follower Core self-evaluation and leadership preference}

Research on self-concept suggests that self-knowledge influences an individual's organization and sense-making of memory and behavior (Kihlstrom, Beer, \& Klein 2003). In relation to leadership preference, individuals project their own attributes onto their ideal leaders, particularly when the attributes are viewed as positive, exhibiting a self-serving pattern (Dunning et al. 1991). Overall, it is found there is a correspondence between individuals' self-perception and their leadership prototypes (Foti et al. 2012).

CSE is a higher order concept representing the fundamental evaluations that people make about themselves and their functioning in their environment (Judge et al. 2002; Judge et al. 1997). It is a broad personality trait indicated by four narrower traits: self-esteem, that is, beliefs about one's overall self-worth; generalized self-efficacy, or beliefs about how well one can perform across situations; locus of control, or beliefs about whether internal or external factors cause events in one's life; and neuroticism, described as the degree of control over emotional reactions (Judge et al. 1997). In general, individuals with high CSE consistently appraise themselves as capable, worthy and in control of their life (Judge et al. 2004).

Authoritarian leadership accentuates a leader's personal authority and dominance over subordinates and demands unquestioned obedience from followers (Farh and Cheng 2000). These dominant behaviors convey a message of self-confidence, self-worth and strong belief in one's ability to control everything (Maslow 1942). This might share similarities with high CSEs who believe that their abilities are above average (Baumeister et al. 2003). Indeed, Foti et al. (2012) find that those who rate themselves as above average 
in sensitivity (e.g., helpful), intelligence (e.g., knowledgeable) and dedication (e.g., hardworking) tend to prefer prototypical leadership (a concept similar to transformational leadership in their study) or autocratic leadership compared to other leadership styles. Given the similarity between high CSEs and authoritarian leaders in self-confidence, selfworth and strong control capability, we expect there would be a positive relationship between followers' CSE and preference for authoritarian leadership.

\section{H5: Followers' CSE is positively related to their preference for authoritarian leadership.}

Benevolent leaders avoid publicly embarrassing their followers, provide followers with social support and care about followers' family members and personal lives. As noted above, a leader's benevolence is much appreciated in Chinese society because of the influence of Confucianism. Because high CSEs tend to see themselves as possessing desirable attributes (Baumeister et al. 2003; Sedikides and Gregg 2007), it is likely that they believe they are similar to benevolent leaders in this respect and therefore prefer to have a benevolent leader.

H6: Followers' CSE is positively related to their preference for benevolent leadership.

In this vein, because leader morality is highly regarded in China (Ling et al. 2000) and high CSEs are more likely to regard themselves as having flattering attributes (Baumeister et al. 2003; Sedikides and Gregg 2007). They are more likely to perceive that their level of morality is above average and see this as something they share with moral leaders. Thus, we predict that followers' CSE is positively related with their preference for moral leadership.

\section{H7: Followers' CSE is positively related to their preference for moral leadership.}

Transformational leaders are characterized by high levels of confidence, dominance and strong beliefs in their ability to control events (Bass 1985, 1990; Eden 1992). Their emotions are stable and absent of excessive anxiety (Bono and Judge 2004), which instill faith in a better future on the part of followers (Shamir et al. 1994). Recently a handful of studies demonstrate that leaders high in CSE are more likely to be rated as transformational leaders (Judge et al. 2009; Hu et al. 2012; Resick et al. 2009). Given the similarity between high CSEs and transformational leadership, we expect that they are likely to project their own attributes to their concept of leaders and develop a preference for transformational leadership (Foti et al. 2012). We hypothesize:

H8: Followers' CSE is positively related to their preference for transformational leadership.

\section{Methods}

\section{Participants and procedures}

Participants consist of 423 Chinese employees. They were recruited from the sample pool of a Survey Company in 2011. All the participants received an email inviting them to fill out the questionnaire. Those who submitted the questionnaire were rewarded with points which can be exchanged for vouchers once they accumulated a certain 
amount. Six hundred seventeen questionnaires were returned within two weeks. Since the online system recorded respondents' starting and completion time, we were able to identify those questionnaires completed in a short time. We deleted those completed in less than three minutes, as we estimate that it should have taken longer. We also deleted the ones in which there were too many missing values. From the remaining questionnaires we further excluded those in which the participants reported that they have no work experience $(N=39)$, since our aim is to examine the leadership preferences of employees. The final sample included 423 participants.

$219(51.8 \%)$ of the participants were male, with a mean age of $32.62(S D=9.44)$. Most of them were less than 30 years old $(N=214,50.6 \%)$. Participants with a bachelor degree made up the largest part of the sample $(N=201,47.5 \%)$; followed by those with a junior college degree $(N=118,27.9 \%)$. Eighty two $(19.4 \%)$ participants had a degree below or equivalent to high school. Twenty two $(5.2 \%)$ participants had a postgraduate degree. One hundred ninety-eight participants (46.8\%) reported that they had subordinates. Thus the sample over-represented the leadership preferences of young and educated employees in managerial positions. The participants worked in various industries ranging from education, non-profit organizations and government to manufacturing and service industries.

\section{Measures}

The dependent variables in the study are preferences for three components of paternalistic leadership (i.e., preference for authoritarian, benevolent, and moral leadership) and preference for transformational leadership.

\section{Preference for paternalistic leadership}

Preferences for the three components of paternalistic leadership were measured with the 15-item paternalistic leadership scale developed by Cheng et al. (2000, see also Cheng et al. 2003). We adapted the original instructions. The new instructions read: "Everyone has her/his ideal leader. The ideal leader exhibits certain leadership behaviors. To what extent do you expect your ideal leader to exhibit the following behaviors?" These instructions were also used to measure participants' preference for transformational leadership. Preference for each component of paternalistic leadership was measured by five items on a sixpoint Likert scale ( $1,=$ "don't expect it at all" to 6, "strongly expect it"). An example of authoritarian leadership behavior is "my supervisor always has the last say in the meeting"; benevolent leadership behavior: "my supervisor takes good care of my family members as well"; moral leadership behavior: "my supervisor does not use guanxi (personal relationships) or back-door practices to obtain illicit personal gains". The reliability coefficient (Cronbach's alpha) of the preference for authoritarian leadership scale is 0.79 ; the preference for benevolent leadership scale is 0.78 ; and the preference for moral leadership scale is 0.83 . Responses on each scale were averaged to form a single score. All subsequent scales were created by averaging the items.

\section{Preference for transformational leadership}

Preference for transformational leadership was measured with the 12-item scale of Bass and Avolio (1994). The original scale was a five-point Likert scale. To make the 
responses on this scale comparable with that on the paternalistic leadership preference scale, we changed it into a six-point Likert scale (1, = "don't expect it at all" to 6, "strongly expect it"). The reliability coefficient (Cronbach's alpha) of this scale is 0.86 .

The independent variables in the study are power distance orientation and CSE.

\section{Power distance orientation}

Power distance orientation was measured with the six-item scale developed by Dorfman and Howell (1988). This measure has been validated in the Chinese context (Chen et al. 2014). A sample item is, "In most situations, managers should make decisions without consulting their subordinates". Responses range from 1 (strongly disagree) to 5 (strongly agree). The reliability coefficient (Cronbach's alpha) of this scale is 0.72 .

CSE

CSE was measured with the 12-item scale developed by Judge et al. (2003). The scale has been validated in China (Rode et al. 2012; Sun and Yang 2013). Sample items are "I am confident that I get the success I deserve in life" and "Sometimes when I fail I feel worthless". The five-point Likert scale ranges from 1 (strongly disagree) to 5 (strongly agree). The reliability coefficient (Cronbach's alpha) of this scale is 0.71 .

\section{Control variables}

Past research suggests that men and women have different ideal leader profiles (Epitropaki and Martin 2004; Vecchio and Boatwright 2002), thus we controlled for gender in the analysis. Female was coded as "0" and served as the reference group. Age may reflect generational differences and the influence of modernization in China (Farh and Cheng 2000), hence, we controlled the age group. The age group of less than 30 years old was coded as "0" and served as the reference group. As management level may also affect the idealized leader image (Lord et al. 2001), whether a participant has subordinates was also controlled. Those without subordinates were coded as " 0 ". The educational level of participants was taken as another control variable. The group of respondents with a degree of high school or below was coded as "0".

\section{Common method variance, measure validity and multicollinearity check}

Because all the measures were based on self-reported data collected at one time point, the analysis may be subject to common method variance (Podsakoff et al. 2003). We used Harman's single factor test to investigate the potential influence of common method bias (Podsakoff and Organ 1986). Results of the principal component factor analysis, using varimax rotation, show that the largest factor accounted for only $9.4 \%$ of the variance. This suggests the absence of serious threats of common method bias to the results. Further, we conducted confirmatory factor analysis (CFA). The CFA results show that a six-factor model with items loaded on the constructs they are supposed to measure fitted the data well $\left(\chi^{2}(1160)=2033.86, p<0.01\right.$; CFI $=0.93$, TLI $=0.92$, RMSEA $=0.04)$. The Average Variance Extracted $(\mathrm{AVE})$ of all constructs are equal or above 0.50, except for preference for authoritarian leadership (AVE $=0.45$ ). Adding an additional latent method factor with all items loaded on it, the model failed to converge, suggesting severe ill-fit. Hence, the CFA approach also indicates that a common method factor does not fit the data. 
To check for a potential multicollinearity problem, we examined the Variance Inflation Factor (VIF). All VIFs in the four regression models were below 2, meaning that there is no severe multicollinearity problem in the data (Hair et al. 2009).

\section{Results}

\section{Descriptive analysis}

Means, standard deviations, and correlations among variables are depicted in Table 1. It can be seen that the respondents' average preference for moral leadership is the highest $(M=4.96)$, followed by preference for transformational leadership $(M=4.39)$ and benevolent leadership $(M=3.57)$. The preference for authoritarian leadership is the lowest $(M=2.45)$. The correlation matrix indicates that employees' power distance orientation is positively related to preference for authoritarian leadership $(r=0.52, p<0.01)$, and negatively related to preference for moral leadership $(r=-0.23, p<0.01)$. As to the preference for benevolent leadership and transformational leadership, power distance orientation has no relationship with them ( $r=0.03$ and $r=-0.03$, respectively, n.s.). CSE is positively related with preference for authoritarian leadership $(r=0.24, p<0.01)$, preference for benevolent leadership $(r=0.21, p<0.01)$ and preference for transformational leadership $(r=0.25, p<0.01)$; whereas the correlations between CSE and preference for benevolent leadership is not significant.

\section{Hypothesis testing}

Hypothesis 1 states that Chinese employees will prefer moral and transformational leadership most, followed by benevolent leadership, and authoritarian leadership will be least preferred. To test this hypothesis, we conducted one-way repeated-measures ANOVA, since the data on preferences for the four types of leadership were collected from the same participants and thus dependent. Mauchly's test shows that the assumption of sphericity was violated $\left(\chi^{2}(5)=209.80, p<0.05\right)$, thus we report the results of Huynh-Feldt test. It was found that employees' preferences for the four leadership styles are different $(F(2.34,989.21)=729.63, p<0.01)$. Pairwise post-hoc tests support our hypothesis. They reveal that moral leadership is the most preferred leadership style $(M=4.96)$, followed by transformational leadership $(M=4.38)$ and benevolent leadership ( $M=$ 3.57). Authoritarian leadership is least preferred by the participants $(M=2.45)$. The differences between preferences for any two types of leadership styles are significant at the 0.01 level. The significance test of the pairwise comparison is shown below in Table 2.

Hierarchical multiple regression was employed to test the other hypotheses. The regression results are depicted in Table 3.

Hypothesis 2 states that followers' power distance orientation is positively associated with their preference for authoritarian leadership. In support of Hypothesis 2, the regression coefficient for power distance orientation is significantly positive $(\beta=0.47$, $p<0.01$ ), suggesting that the higher one's power distance orientation is, the more likely he/she would prefer authoritarian leadership.

Hypothesis 3 states that followers' power distance orientation is positively related to their preference for benevolent leadership. The result does not support this hypothesis. 


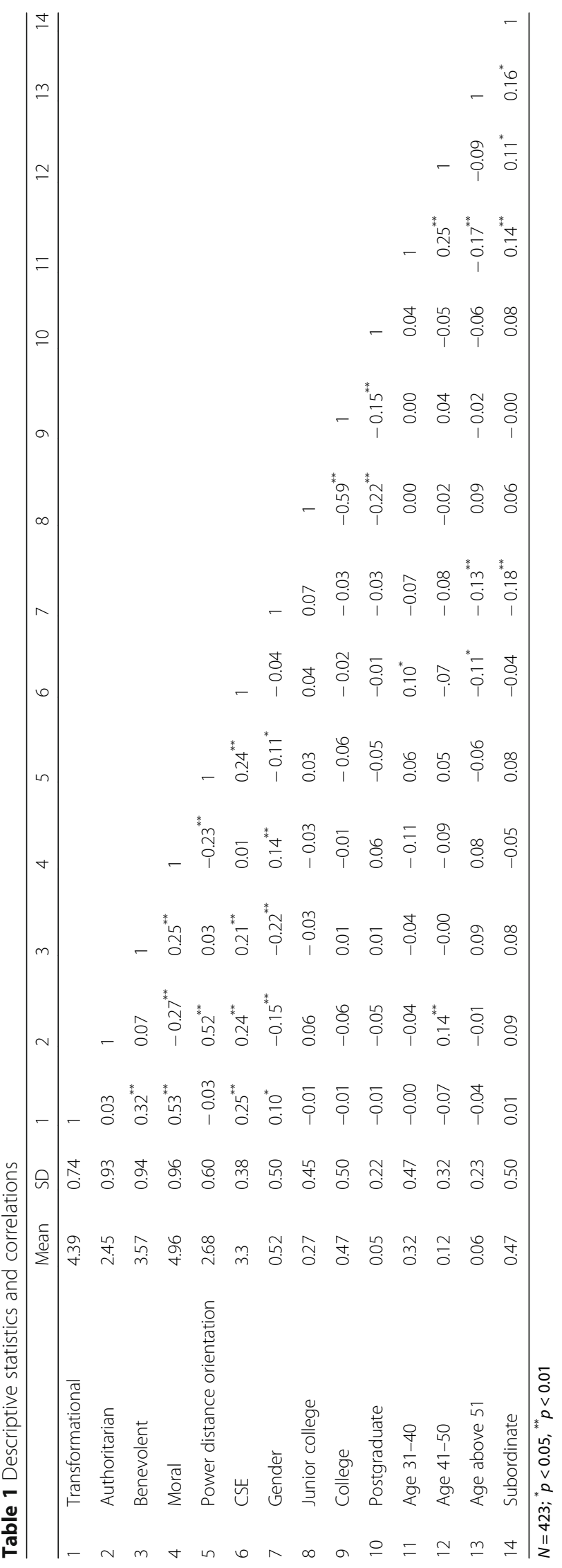


Table 2 Pairwise comparison of leadership preferences

\begin{tabular}{|c|c|c|c|c|c|}
\hline I & Mean(l) & J & $\operatorname{Mean}(J)$ & Mean difference & Significance ${ }^{\mathrm{a}}$ \\
\hline \multirow[t]{3}{*}{ moral } & 4.96 & benevolent & 3.57 & $1.39^{* *}$ & .00 \\
\hline & & authoritarian & 2.45 & $2.51^{* *}$ & .00 \\
\hline & & transformational & 4.39 & $0.57^{* *}$ & .00 \\
\hline \multirow[t]{3}{*}{ benevolent } & 3.57 & moral & 4.96 & $-1.39^{* *}$ & .00 \\
\hline & & authoritarian & 2.45 & $1.12^{* *}$ & .00 \\
\hline & & transformational & 4.39 & $-0.82^{* *}$ & .00 \\
\hline \multirow[t]{3}{*}{ authoritarian } & 2.45 & moral & 4.96 & $-2.51^{* *}$ & .00 \\
\hline & & benevolent & 3.57 & $-1.12^{* *}$ & .00 \\
\hline & & transformational & 4.39 & $-1.94^{* *}$ & .00 \\
\hline \multirow[t]{3}{*}{ transformational } & 4.39 & moral & 4.96 & $-0.57^{* *}$ & .00 \\
\hline & & benevolent & 3.57 & $0.82^{* *}$ & .00 \\
\hline & & authoritarian & 2.45 & $1.94^{* *}$ & .00 \\
\hline
\end{tabular}

${ }^{* *} p<0.01$

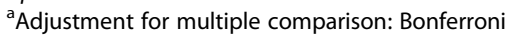

No significant relationship is found between power distance orientation and preference for benevolent leadership $(\beta=-0.04$, n.s.). Thus Hypothesis 3 is not supported.

Hypothesis 4 states that followers' power distance orientation is positively related to their preference for moral leadership. Because the data for moral leadership preference is skewed to the left with most of the respondents showing a high preference for moral leadership, an MLR estimator is used which is robust to data non-normality. We find that the opposite of our hypothesis is supported. Power distance orientation is negatively related to followers' preference for moral leadership $(\beta=-0.22, p<.01)$. Hence, Hypothesis 4 is rejected.

In relation to transformational leadership, no significant relationship is found between power distance orientation and preference for transformational leadership $(\beta=-0.09$, n.s.). As to the relationship between followers' CSE and their preferences for four leadership styles, except that followers' CSE has no significant relationship with their preference for moral leadership $(\beta=0.08$, n.s.), positive relationships are found between followers' CSE and their preference for authoritarian leadership ( $\beta=0.14$, $p<0.01)$, benevolent leadership $(\beta=0.23, p<0.01)$ and transformational leadership $(\beta=0.28, p<0.01)$. Hence, Hypotheses 5,6 and 8 are supported, but not Hypothesis 7 .

With regards to the demographic variables, the regression results show that the male and female participants differ in their preferences for the four types of leadership. The female participants prefer authoritarian leadership more than their male counterparts $(\beta=-0.14, p<0.01)$. However, after entering power distance orientation and CSE, this effect became insignificant $(\beta=-0.08$, n.s.). The female participants also prefer benevolent leadership more than the male participants $(\beta=-0.20, p<0.01)$. In contrast, the male participants prefer moral $(\beta=0.11, p<0.01)$ and transformational leadership $(\beta=0.10, p<0.05)$ more. Age difference is found in participants' preference for authoritarian and moral leadership. Participants aged between 41 and 50 have a stronger preference for authoritarian leadership than those aged below $30(\beta=0.10, p<0.05)$. Participants aged between 31 and 40 have a weaker preference for moral leadership than those aged below $30(\beta=-0.11, p<0.05)$. 


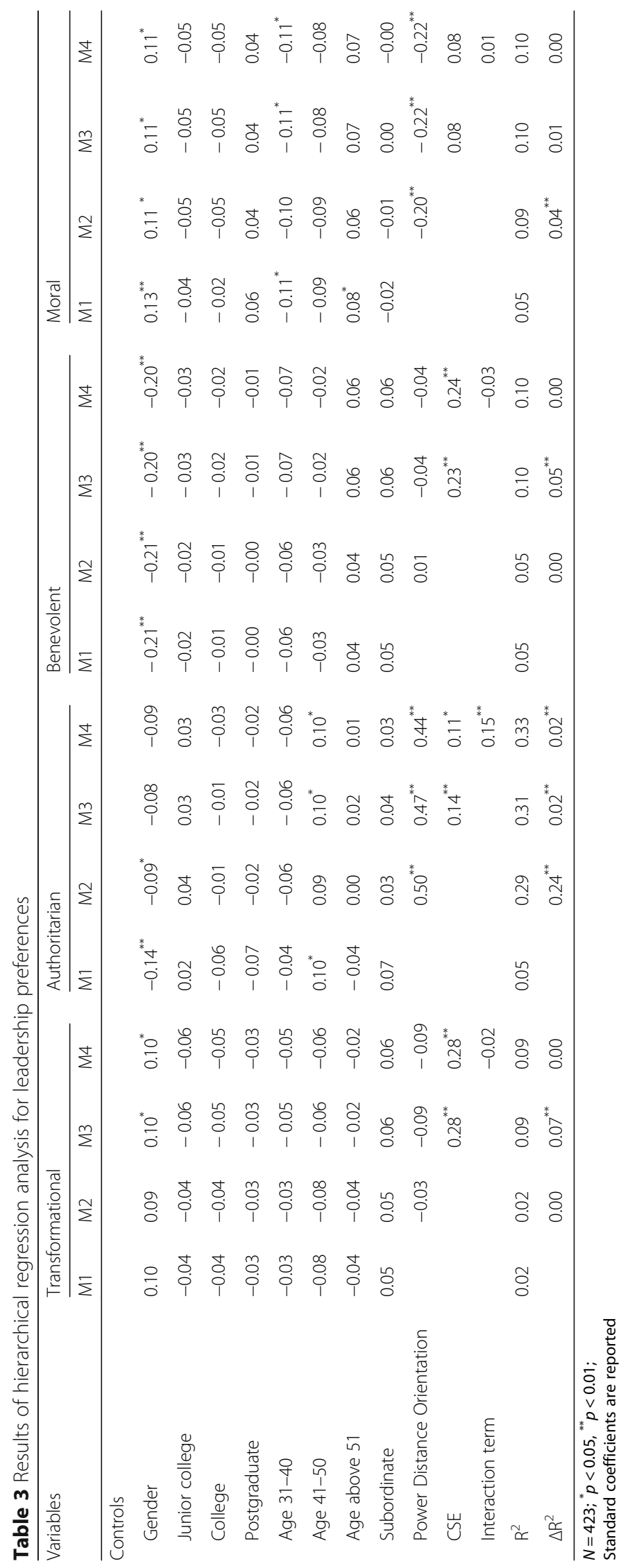


Our model in total explains $31 \%$ of the variance in followers' preference for authoritarian leadership, $10 \%$ variance in their preference for benevolent and moral leadership, and $9 \%$ in their preference for transformational leadership. The proportion of variances explained by power distance orientation and CSE ranges from $5 \%$ to $26 \%$, representing a medium to large effect size (Cohen 1988). Thus we conclude that it is worthwhile to investigate the role of power distance orientation and CSE in leadership preference.

\section{Supplementary analysis}

Although not hypothesize, we examine in an exploratory fashion whether there is any interaction between power distance orientation and CSE. ${ }^{1}$ An interaction effect is found with regard to authoritarian leadership preference (see Table 3, M4). The interaction is positive $(\beta=0.15, p<0.01)$. A moderation graph shows when followers' CSE is high, the relationship between power distance orientation and preference for authoritarian leadership becomes stronger.

\section{Discussion}

In this study we compare Chinese employees' preferences for paternalistic leadership and transformational leadership. Furthermore, we examine how followers' power distance orientation and CSE are related to their leadership preferences. We highlight several important findings. First, our results reveal that Chinese employees have an extremely high expectation of moral leadership and transformational leadership and a moderate expectation of benevolent leaders. In contrast, they prefer authoritarian leadership to the least extent. Second, we find that followers' high power distance orientation is positively related to their preference for authoritarian leadership, negatively related to their preference for moral leadership and unrelated to their preference for benevolent and transformational leadership. Third, there is a positive relationship between CSE and preference for authoritarian, benevolent and transformational leadership. Last but not least, we find a significant interaction between power distance orientation and CSE on authoritarian leadership preference (Fig. 1).

It is worthwhile to point out that these conclusions are based on data gathered from relatively young professionals. The un-supported hypotheses about the relationship between power distance orientation and preference for benevolent leadership and

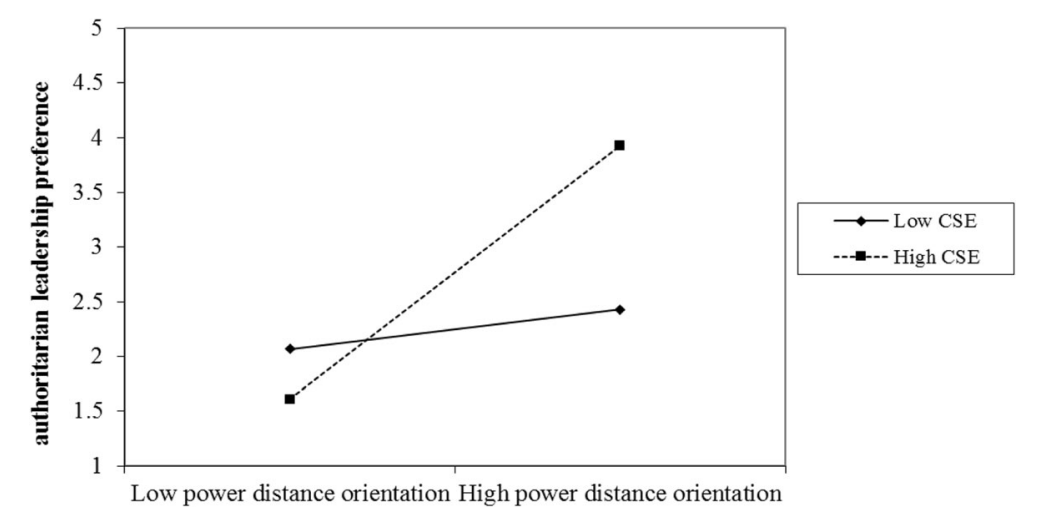

Fig. 1 The moderation effect of power distance orientation and CSE on authoritarian leadership preference 
moral leadership call for further elaborations of the potential relationships and empirical studies. One of the possible explanations is the relationships among these variables are not directly related to each other. It has been argued that cultural value orientation may serve as a facilitator or barrier to transformational leadership effects (Ehrhart and Klein 2001; Howel \& Shamir 2005; Kirkman et al. 2009) and studies have demonstrated that power distance orientation has both direct and moderating roles in shaping followers' reactions to transformational leaders (Kirkman et al. 2009). Furthermore, studies also show a three-way interaction effect of power distance orientation, procedural justice, and ethical leadership (a similar construct with moral leadership) on the perception of job insecurity (Loi et al. 2012).

\section{Theoretical contributions}

Our research contributes to the literature in several important ways. First, we extend the leadership preference literature by comparing followers' preference for paternalistic leadership, a prevalent leadership style in Asia and other regions in the world, and transformational leadership, a leadership style much advocated for in western culture. In doing so, we bring contexts into leadership preference research. Combined with prior research, our study indicates that while leadership preference is influenced by the context in which followers reside, preference for certain leadership styles can also be universal. Our results show that Chinese employees yearn for moral leadership. The high expectation of moral leadership has been demonstrated to be a distinct factor of Chinese implicit leadership theories which differ from the implicit leadership theories in western countries (Ling et al. 2000). On the other hand, Chinese employees' high expectations of transformational leadership confirm the finding of Den Hartog et al. (1999) that many attributes of transformational leadership are universally endorsed.

Second, this study advances our understanding of followers' cultural value orientation in leadership preference. The strong relationship between employees' power distance orientation and preference for authoritarian leadership suggests that employees' dependent mind-set and respect for hierarchy are the premise of authoritarian leadership. Contrary to our hypothesis, a negative relationship between power distance orientation and preference for moral leadership is found. It seems for those with a high power distance orientation, morality is less likely to be a salient attribute of their ideal leader. Thus, they may be less likely to call immoral leadership behaviors into question whenever such behaviors arise. Because follower responses put important constraints on leader's behaviors (Howell and Shamir 2005), we expect that followers with a high power distance orientation may not be in a strong position to constrain immoral leadership behaviors. The independence of power distance orientation from preference for transformational leadership provides the micro-foundation for the universal endorsement of transformational/charismatic leadership (Den Hartog, et al. 1999). It concurs with the argument of Antonakis and Atwarter (2002) that social distance, which is a concept that includes power distance, is not a necessary condition for the emergence of transformational leadership.

Third, we make a contribution to the literature on followers' self-concept and leadership process. Although previous studies find that individuals may seek both 
symmetrical and compensatory traits in their idealized leaders (Ehrhart and Klein 2001; Keller 1999), our findings indicate that followers are more likely to be attracted by those leaders who are perceived as similar to themselves. It is possible that the ideal leader of a follower represents his/her possible self, which defines who the follower could be in the future (Markus and Nurius 1986). Because imagining one's possible self is self-enhancing, followers would see the ideal leaders as similar to themselves (Lockwood and Kunda 1997). This finding is also consistent with the argument of Lord et al. (1999) that perceived similarities between followers' and leaders' self-views present an important basis for liking and identification.

The interaction effect between power distance orientation and CSE with regard to authoritarian leadership preference is interesting. It suggests that high CSEs are more likely to project their own power distance orientation onto their ideal leaders. One possible explanation is that high CSEs view power inequality in a more positive light and therefore are more likely to project this positive attribute onto their ideal leader to enhance their self-concept. Indeed, the extreme of self-esteem is narcissism, which is found to fuel a sense of entitlement to power (Rosenthal \& Pittinsky 2006).

\section{Practical implications}

Our study has several practical implications. First, it suggests that if managers working in China can demonstrate their morality to employees or display transformational leadership behaviors, they are likely to be recognized by many as a leader, because their behaviors would be congruent with many employees' ideal leadership behaviors. At the same time, they should avoid displaying authoritarian leadership behaviors, especially not to the young and educated Chinese employees represented by our sample. Although China has been traditionally regarded as a country high in power distance and it is suggested that in high power distance countries an idealized leader is a benevolent authoritarian (Hofstede et al. 2010), our research paints a different picture. It illustrates that contemporary Chinese employees do not fully accept hierarchy in organizations any longer. Compliance to authority seems no longer to be a common value in China, which is indicated by the low mean of our participants' power distance orientation. Therefore, it is necessary that managers treat contemporary Chinese employees in an egalitarian way.

Second, this study provides implications for personnel selection. As revealed by our research, demographics, power distance orientation and CSE explain 9\%-31\% of employees' leadership preferences. Because these attributes are relatively stable, organizations should make sure that person-supervisor fit can be realized through rigorous personnel selection. Employees whose leadership preference fits with their future supervisor's leadership style, are more likely to experience supervisor satisfaction and have a good leader-member exchange relationship (Epitropaki and Martin 2005). Although implicit leadership theories and the value orientations and self-concept that underlie them are relatively stable, it does not mean they could not be changed at all. It has been found that follower age, occupation and educational level (Ling et al. 2000) and their leadership experience (Epitropaki and Martin 2004) shape their leadership prototypes. Job rotations and expatriate job assignments exposing employees to different leaders or even involving them in leadership responsibilities for a relatively long period are likely to change their leadership prototypes. 
Increasing workplace diversification seems to be a trend in many countries. Diverse members bring rich cognitive resources which teams and organizations can capitalize on (Hambrick et al. 1996), but they also bring different values and self-concepts into the workplace, which are associated with different leadership preferences. To manage a diversified team or organization, the ability to adjust leadership behaviors is a key competence of successful leaders (Lord et al. 1999). This requirement has a number of implications for leadership development. First, training that equips leaders with knowledge and skills coping with different followers might be highly useful. Second, one would expect that leaders who have work experience with diverse followers would acquire experiences from this process and learn how to better deal with different followers. Thus, systematic career management such as expatriate job appointments or job rotation would help leaders to understand the preferences of different followers and develop effective coping strategies.

\section{Limitations and future directions}

While our research makes both theoretical and practical contributions, it is not without limitations. First, online data collection limits our sample to those who have access to the internet. Therefore, our sample over-represents young educated Chinese employees. Correspondingly, the findings should be interpreted with the characteristics of our sample in mind. Future research can apply a stratified sampling strategy and get a more comprehensive picture of Chinese employees' leadership preferences. Second, the selfreported data makes our findings subject to the threat of common-method bias. Although Harman's test reveals that common method bias does not severely threaten the validity of our results, its influence cannot be completely excluded. Third, in our instructions we do not confine participants' ideal leader to a specific industry or occupation; thus the leadership our research taps into is the leadership at the superordinate or basic level which does not include detailed industry information (Lord et al. 1984). Future research revealing and contrasting the leadership prototypes in multiple industries is worthwhile. Finally, future research could examine the potential interactive effects of personal and organizational factors on followers' leadership preferences.

Overall, the present study has outlined Chinese employees' leadership preference and demonstrated that followers' power distance orientation and their self-concept are associated with their leadership preferences. It has both theoretical implications for leadership study and practical implications for human resource management and leadership development.

\section{Endnotes}

${ }^{1}$ We thank an anonymous reviewer for suggesting this.

Acknowledgements

We highly appreciate the valuable comments and suggestions from Dr. Jason Shaw, Dr. Lynda Song, and others in the seminar organized by the Business School of Renmin University of China in September 2017.

Funding

The paper was partially funded by National Natural Sciences Foundation of China, No. 71272158. 


\section{Authors' contributions}

$\mathrm{CH}$ and JM worked together by discussions on developing research questions and theoretical models. $\mathrm{CH}$ proposed the preliminary research design and JM improved the research design by adding the moderator of CSE. CH designed the questionnaire and JM improved it by adding more demographic information questions. $\mathrm{CH}$ collected the data and performed the data analyses. $\mathrm{CH}$ wrote the first draft and JM improved dramatically the introduction and discussion sections. Both worked together on the revision based on the comments of reviewers based on extensive discussions. Both read and approved the final manuscript.

\section{Competing interests}

The authors declare that they have no competing interests.

\section{Publisher's Note}

Springer Nature remains neutral with regard to jurisdictional claims in published maps and institutional affiliations.

\section{Author details}

'Queen's University Belfast, Queen's Management School, Room 02.006, 185 Stranmillis Road, Northern Ireland BT9 5EE,

UK. ${ }^{2}$ School of Labor and Human Resources, Renmin University of China, Beijing, China.

Received: 1 November 2017 Accepted: 6 March 2018

Published online: 24 March 2018

\section{References}

Alipour, K. K., Mohammed, S., \& Martinez, P. N. (2017). Incorporating temporality into implicit leadership and followership theories: Exploring inconsistencies between time-based expectations and actual behaviors. The Leadership Quarterly, 28(2), 300-316.

Antonakis, J., \& Atwarter, L. (2002). Leader distance: A review and a proposed theory. Leadership Quarterly, 13, 673-704.

Aycan, Z. (2006). Paternalism: Towards conceptual refinement and operationalization. In K. S. Yang, K. K. Kwang, \& U. Kim (Eds.), Indigenous and cultural psychology: Understanding people in context (pp. 445-466). London: Sage.

Bass, B. M. (1985). Leadership and performance beyond expectations. New York: Free Press.

Bass, B. M. (1990). Bass and Stogdill's handbook of leadership (3rd ed.). New York: Free Press.

Bass, B. M., \& Avolio, B. J. (1994). Improving organizational effectiveness through transformational leadership. Thousand Oaks: Sage.

Bass, B. M., \& Riggio, R. E. (2006). Transformational leadership (2nd ed.). Mahwah: Lawrence Erlbaum Associates.

Bass, B. M., \& Steidlmeier, P. (1999). Ethics, character, and authentic transformational leadership behavior. Leadership Quarterly, 10(2), 181-217

Baumeister, R. F., Campbell, J. D., Krueger, J. I., \& Vohs, K. D. (2003). Does high self-esteem cause better performance, interpersonal success, happiness, or healthier lifestyles? Psychological Science in the Public Interest, 4(1), 1-44.

Bing, S. (2004). Sun Tzu was a Sissy: Conquer Your Enemies, Promote Your Friends, and Wage the Real Art of War. New York: HarperCollins.

Bono, J. E., \& Judge, T. A. (2004). Personality and transformational and transactional leadership: A meta-analysis. Journal of Applied Psychology, 89(5), 901-910.

Brain, K., \& Lewis, D. (2004). Exploring leadership preferences in multicultural workgroups: An Australian case study. The Leadership \& Organization Development Journal, 25(3), 263-278.

Budin, D. K. A., \& Wafa, S. A. (2015). The relationship between culture and leadership style preference among Malay-Brunei, Bajau and Kadazan-Dusun community in Sabah, Malaysia. Journal of Management Development, 34(10), 1202-1210

Burns, J. M. (1978). Leadership. New York: Harper \& Row.

Chen, C., Liao, J., \& Wen, P. (2014). Why does formal mentoring matter? The mediating role of psychological safety and the moderating role of power distance orientation in the Chinese context. The International Journal of Human Resource Management, 25(8), 1112-1130.

Cheng, B.-S. (1995). Paternalistic authority and leadership: A case study of a Taiwanese CEO. Bulletin of the Institute of Ethnology Academic Sinica, 79, 119-173 (In Chinese).

Cheng, B. S., Chou, L. F., \& Farh, J. L. (2000). A triad model of paternalistic leadership: The constructs and measurement. Indigenous Psychological Research in Chinese societies, 14, 3-64 (in Chinese).

Cheng, B. S., Chou, L. F., Huang, M. P., Farh, J. L., \& Peng, S. (2003). A triad model of paternalistic leadership: Evidence from business organization in mainland China. Indigenous Psychological Research in Chinese Societies, 20, 209-250 (in Chinese).

Cheng, B. S., Chou, L. F., Wu, T. Y., Huang, M. P., \& Farh, J. L. (2004). Paternalistic leadership and subordinate responses: Establishing a leadership model in Chinese organizations. Asian Journal of Social Psychology, 7, 89-117.

Cheng, B. S., Huang, M. P., \& Chou, L. F. (2002). 'Paternalistic Leadership and its Effectiveness: Evidence from Chinese Organization Teams'. Journal of Psychology in Chinese Societies, 3, 85-112 (in Chinese).

Chia, J. S., Pyun, D. Y., \& Kwon, H. H. (2015). The impact of congruence between perceived and preferred leadership on satisfaction among college student-athletes in Singapore. Asia Pacific Journal of Education, 35(4), 498-513.

Cohen, J. (1988). "Statistical power analyses for the social sciences." Hillsdale: Lawrence Erlbauni Associates.

Conger, J. A., \& Kanungo, R. N. (1998). Charismatic leadership in organizations. Thousand Oaks: Sage.

Cooke, F. L. (2011). Labour market disparities and inequalities. In P. Sheldon, S. Kim, Y. Li, \& M. Warner (Eds.), China's changing workplace: Dynamism, diversity and disparity (pp. 259-276). London: Routledge.

Dansereau, F., Yammarino, F. J., Markham, Alutto, J. A., Newman, J., Dumas, M., Nachman, S. A., et al. (1995). Individualized leadership: A multiple-level approach. Leadership Quarterly, 6(3), 413-450. 
Den Hartog, D. N., House, R. J., Hanges, P., Ruiz-Quintanilla, S. A., Dorfman, P. W., \& GLOBE Associates. (1999). Culture specific and cross-culturally generalizable implicit leadership theories: Are attributes of charismatic/transformational leadership universally endorsed? Leadership Quarterly, 10(2), 219-256.

Dorfman, P. W., \& Howell, J. P. (1988). Dimensions of National Culture and effective leadership patterns: Hofstede revisited. Advances in International Comparative Management, 3, 127-150.

Dunfee, T. W., \& Warren, D. E. (2001). Is guanxi ethical? A normative analysis of doing business in China. Journal of Business Ethics, 32, 191-204.

Dunning, D., Perie, M., \& Story, A. L. (1991). Self-serving prototypes of social categories. Journal of Personality and Social Psychology, 61, 957-968.

Dvir, T., Eden, D., Avolio, B. J., \& Shamir, B. (2002). Impacts of transformational leadership on follower development and performance: A field experiment. Academy of Management Journal, 45(4), 735-744.

Dvir, T., \& Shamir, B. (2003). Follower developmental characteristics as predicting transformational leadership: A longitudinal field study. Leadership Quarterly, 14, 327-344.

Eden, D. (1992). Leadership and expectations: Pygmalion effects and other self-fulfilling prophecies in organizations. Leadership Quarterly, 3, 271-305.

Eden, D., \& Leviatan, U. (1975). Implicit leadership theory as a determinant of the factor structure underlying supervisory behavior scales. Journal of Applied Psychology, 60(6), 736-741.

Ehrhart, M. G., \& Klein, K. J. (2001). Predicting followers' preferences for charismatic leadership: The influence of follower values and personality. Leadership Quarterly, 12, 153-179.

Epitropaki, O., \& Martin, R. (2004). Implicit leadership theories in applied settings: Factor structure, generalizability, and stability over time. Journal of Applied Psychology, 89(2), 293-310.

Epitropaki, O., \& Martin, R. (2005). From ideal to real: A longitudinal study of the role of implicit leadership theories on leader-member exchanges and employee outcomes. Journal of Applied Psychology, 90(4), 659-676.

Eylon, D., \& Au, K. Y. (1999). Exploring empowerment cross-cultural differences along the power distance dimensions. International Journal of Intercultural Relations, 23(3), 373-385.

Farh, J.-L., \& Cheng, B.-S. (2000). A cultural analysis of paternalistic leadership in Chinese organizations. In J. T. Li, A. S. Tsui, \& E. Weldon (Eds.), Management and organizations in the Chinese contexts (pp. 84-127). London: MacMillan.

Farh, J. L., Cheng, B. S., Chou, L. F., \& Chu, X. P. (2006). Authority and benevolence: Employee responses to paternalistic leadership in China. In A. S. Tsui, Y. Bian, \& L. Cheng (Eds.), China's domestic private firms: Multidisciplinary perspectives on management and performance (pp. 230-260). New York: Sharpe.

Farh, J. L., Liang, J., Chou, L. F., \& Cheng, B. S. (2008). Paternalistic leadership in Chinese organizations: Research progress and future research directions. In C. C. Chen \& Y. T. Lee (Eds.), Leadership and management in China: Philosophies, theories, and practices (pp. 171-205). London: Cambridge University Press.

Fein, E. C., Tziner, A., \& Vasiliu, C. (2010). Age cohort effects, gender, and Romanian leadership preferences. Journal of Management Development, 29(4), 364-376.

Foti, R. J., Bray, B. C., Thompson, N. J., \& Allgood, S. F. (2012). Know thy self, know thy leader: Contributions of a pattern-oriented approach to examining leader perceptions. Leadership Quarterly, 23(4), 702-717.

Foti, R. J., Hansbrough, T. K., Epitropaki, O., \& Coyle, P. T. (2017). Dynamic viewpoints on implicit leadership and followership theories: Approaches, findings, and future directions. Leadership Quarterly, 28(2), 261-267.

Foti, R. J., \& Luch, C. H. (1992). The influence of individual differences on the perception and categorization of leaders. Leadership Quarterly, 3, 55-66.

Hair, J. F., Black, W. C., Babin, B. J., \& Anderson, R. E. (2009). Multivariate data analysis (7th ed.). Upper Saddle River: Pearson Education.

Hambrick, D. C., Cho, T. S., \& Chen, M.-J. (1996). The influence of top management team heterogeneity on firm's competitive moves. Administrative Science Quarterly, 41(4), 659-684.

Ho, D. Y. F. (1987). Fatherhood in Chinese culture. In M. E. Lamb (Ed.), The Father's role: Cross-cultural perspectives (pp. 227-245). Hillsdale: Erlbaum.

Hofstede, G. (1997). Cultures and organizations: Software of the mind (2nd ed.). New York: McGraw-Hill.

Hofstede, G., Hofstede, G. J., \& Minkov, M. (2010). Cultures and organizations: Software of the mind (3rd ed.). London: McGraw-Hill.

Howell, J. M., \& Shamir, B. (2005). The role of followers in the charismatic leadership process: Relationships and their consequences. Academy of Management Review, 30(1), 96-112.

Hu, J., Wang, Z., Liden, R. C., \& Sun, J. M. (2012). The influence of leader core self-evaluation on follower reports of transformational leadership. Leadership Quarterly, 23, 860-868.

Jia, L., Song, J., Li, C., Cui, R., \& Chen, Y. (2007). Leadership styles and employees' job-related attitudes: An empirical study on the mediating effects of reciprocity and trust. Frontiers of Business Research in China, 1(4), 574-605.

Judge, T. A. (2009). Core self-evaluations and work success. Current Directions in Psychological Science., 18(1), 58-62.

Judge, T. A., Erez, A., Bono, J. E., \& Thoresen, C. J. (2002). 'Are Measures of Self-Esteem, Neuroticism, Locus of Control, and Generalized Self-Efficacy Indicators of a Common Core Construct?'. Journal of Personality and Social Psychology, 83, 693-710.

Judge, T. A., Erez, A., Bono, J. E., \& Thoresen, C. J. (2003). The core self-evaluations scale: Development of a measure. Personnel Psychology, 56, 303-331.

Judge, T. A., Locke, E. A., \& Durham, C. C. (1997). The dispositional causes of job satisfaction: A core evaluations approach. Research in Organizational Behavior, 19, 151-188.

Judge, T. A., Piccolo, R. F., \& Kosalka, T. (2009). The bright and dark sides of leader traits: A review and theoretical extension of the leader trait paradigm. Leadership Quarterly, 20,855-875.

Judge, T. A., Van Vianen, A. E. M., \& De Pater, I. E. (2004). Emotional stability, core self-evaluations, and job outcomes: A review of the evidence and an agenda for future research. Human Performance, 17(3), 325-346.

Junker, N. M., \& van Dick, R. (2014). Implicit theories in organizational settings: A systematic review and research agenda of implicit leadership and followership theories. Leadership Quarterly, 25(6), 1154-1173.

Kark, R., Shamir, B., \& Chen, G. (2003). The two faces of transformational leadership: Empowerment and dependency. Journal of Applied Psychology, 88(2), 246-255. 
Katz, D., \& Kahn, R. L. (1978). The social psychology of organizations. New York: Wiley.

Keller, R. T. (1999). Images of the familiar: Individual differences and implicit leadership theories. Leadership Quarterly, 10(4), 589-607.

Keller, R. T. (2006). Transformational leadership, initiating structure, and substitutes for leadership: A konggitudinal study of research and development project team performance. Journal of Applied Psychology, 91(1), 202-210.

Kihlstrom, J. F., Beer, J. S., \& Klein, S. B. (2003). Self and identity as memory. In M. R. Leary \& J. P. Tangney (Eds.), Handbook of self and identity (pp. 68-90). New York: The Guilford Press.

Kirkman, B. L., Chen, G., Farh, J.L., Chen, Z. X., \& Lowe, K. B. (2009). Individual power distance orientation and follower reactions to transformational leaders: A cross-level, cross-cultural examination. Academy of Management Journal, 52(4), 744-764.

Li, C., \& Shi, K. (2008). The structure and measurement of transformational leadership in China. Frontier of Business Research in China, 2(4), 571-590.

Li, C., Zhao, H., \& Begley, T. M. (2015). Transformational leadership dimensions and employee creativity in China: A cross-level analysis. Journal of Business Research, 68(6), 1149-1156.

Li, Y., \& Sun, J.-M. (2015). Traditional Chinese leadership and employee voice behavior: A cross-level examination. Leadership Quarterly., 26(2), 172-189.

Ling, W., Chia, R. C., \& Fang, L. (2000). Chinese implicit leadership theory. Journal of Social Psychology, 140(6), 729-739.

Lockwood, P., \& Kunda, Z. (1997). Superstars and me: Predicting the impact of role models on the self. Journal of Personality and Social Psychology, 73, 91-103.

Loi, R., Lam, L. W., \& Chan, K. W. (2012). Coping with job insecurity: The role of procedurural justice, ethical leadership and power distance orientation. Journal of Business Ethics, 108(3), 361-372.

Lord, R. G., Brown, D. J., \& Freiberg, S. J. (1999). Understanding the dynamics of leadership: The role of follower self-concepts in the leader/follower relationship. Organizational Behavior and Human Decision Processes, 78(3), 167-203.

Lord, R. G., Brown, D. J., \& Harvey, J. L. (2001). System constraints on leadership perceptions, behavior and influence: An example of connectionist level processes. In M. A. Hogg \& R. S. Tindale (Eds.), Blackwell handbook of social psychology: Group processes. Oxford: Blackwell.

Lord, R. G., Foti, R. J., \& De Vader, C. (1984). A test of leadership categorization theory: Internal structure, information processing, and leadership perceptions. Organizational Behavior and Human Performance, 34, 343-378.

Lord, R. G., \& Smith, J. E. (1983). Theoretical, information-processing, and situational factors affecting attribution theory models of organizational behavior. Academy of Management Review, 8, 50-60.

Markus, H., \& Nurius, P. (1986). Possible selves. American Psychologist, 41, 954-969.

Maslow, A. H. (1942). Self-esteem (dominance-feeling) and sexuality in women. Journal of Social Psychology, 16(2), 259-294.

McElwee, R. O. B., Dunning, D., Tan, P. L., \& Hollmann, S. (2001). Evaluating others: The role of who we are versus what we think traits mean. Basic and Applied Social Psychology, 23(2), 123-136.

Pelligrini, E. K., \& Scandura, T. A. (2006). Leader-member exchange (LMX), paternalism and delegation in the Turkish business culture: An empirical investigation. Journal of International Business Studies, 37(2), 264-279.

Pelligrini, E. K., \& Scandura, T. A. (2008). Paternalistic leadership: A review and agenda for future research. Journal of Management, 34, 566-593.

Podsakoff, P. M., MacKenzie, S. B., Lee, J. Y., \& Podsakoff, N. P. (2003). Common method biases in behavior research: A critical review of the literature and recommended remedies. Journal of Applied Psychology, 88, 879-903.

Podsakoff, P. M., \& Organ, D. (1986). Self-reports in organizational research: Problems and prospects. Journal of Management, $12,531-544$

Redding, S. G. (1990). The spirit of Chinese capitalism. New York: Walter de Gruyter.

Resick, C. J., Whitman, D. S., Weingarden, S. M., \& Hiller, N. J. (2009). The bright-side and dark-side of CEO personality: Examinaing core self-evaluation, narcissism, transformational leadership, and strategic influence. Journal of Applied Psychology, 94(6), 1365-1381.

Rode, J. C., Judge, T. A., \& Sun, J. M. (2012). Incremental validity of core self-evaluations in the presence of other self-concepts traits. Journal of Leadership \& Organization Studies, 19(3), 326-340.

Rogiest, S., Segers, J., \& van Witteloostuijn, A. (2018). Matchmaking in organizational change: Does every employee value participatory leadership? An empirical study. Scandinavian Journal of Management, 34(1), 1-8.

Rosenthal, S. A., \& Pittinsky, T. L. (2006). "Narcissistic leadership." The Leadership Quarterly, 17(6), 617-633.

Sedikides, C., \& Gregg, A. P. (2007). Portraits of the self. In M. A. Hogg \& J. Cooper (Eds.), Sage handbook of social psychology (pp. 93-122). Thousand Oaks: Sage.

Shamir, B. (1995). Social distance and charisma: Theoretical notes and an exploratory study. Leadership Quarterly, 6(1), 19-47.

Shamir, B., Arthur, M. B., \& House, R. J. (1994). The rhetoric of charismatic leadership: A theoretical extension, a case study and implications for research. Leadership Quarterly, 5, 25-42.

Shamir, B., Pillai, R., Bligh, M. C., \& Uhl-Bien, M. (Eds.). (2007). Follower-centered perspectives on leadership: A tribute to the memory of James R. Meindl. Greenwich, CT: Inform. Age.

Sheldon, P., Kim, S., Li, Y., \& Warner, M. (Eds.). (2011). China's changing workplace: Dynamism, diversity and disparity. London: Routledge.

Shin, S. J., \& Zhou, J. (2003). Transformational leadership, conservation, and creativity: Evidence from Korea. Academy of Management Journal, 46(6), 703-714.

Silin, R. H. (1976). Leadership and values: The organization of large scale Taiwanese enterprises. Cambridge: Harvard University Press.

Singer, M. S., \& Singer, A. E. (2001). Situational constraints on transformational versus transactional leadership behavior, subordinates' leadership preference and satisfaction. Journal of Social Psychology, 130(3), 385-396.

Subramaniam, A., Othman, R., \& Sambasivan, M. (2010). Implicit leadership theory among Malaysian managers: Impact of the leadership expectation gap on leader-member exchange quality. Leadership \& Organization Development Journal, 31(4), 351-371.

Sun, J. M., \& Yang, T. (2013). The psychometric properties of core self-evaluations scale in the Chinese context. Houston: Paper presented at the 28th Annual Conference of the Society for Industrial and Organizational Psychology.

Sun, W., Xu, A., \& Shang, Y. (2014). Transformational leadership, team climate, and team performance within the NPD team: Evidence from China. Asia Pacific Journal of Management, 31(1), 127-147. 
Thoroughgood, C. N., \& Sawyer, K. B. (2018). "Who wants to follow the leader? Using personality and work value profiles to predict preferences for charismatic, ideological, and pragmatic styles of leading." Journal of Business and Psychology, 33(2), 181-202.

Vecchio, R. P., \& Boatwright, K. J. (2002). Preferences for idealized styles of supervision. Leadership Quarterly, 13, 327-342.

Vecchio, R. P., \& Sussman, M. (1989). Preference for forms of supervisory social influence. Journal of Organizational Behavior, 10(2), 135-143.

Walumba, F. O., Wang, P., Lawler, J. J., \& Shi, K. (2004). The role of collective efficacy in the relations between transformational leadership and work outcomes'. Journal of Occupational and Organizational Psychology, 77, 515-530.

Wang, H., Law, K. S., Hackett, R. D., Wang, D., \& Chen, Z. X. (2005). Leader-member exchange as a mediator of the relationship between transformational leadership and followers' performance and organizational citizenship behavior. Academy of Management Journal, 48(3), 420-432.

Warner, M. (2004). "Human resource management in China revisited: introduction." The International Journal of Human Resource Management, 15(4-5), 617-634.

Wu, M., Huang, X., Li, C., \& Liu, W. (2012). Perceived interactional justice and trust-in-supervisor as mediators for paternalistic leadership. Management and Organization Review, 8(1), 97-121.

Wu, M., Huang, X., Xu, J. P., Yan, H., \& Shi, K. (2007). A comparative study of transactional, transformational and paternalistic leadership behaviors. Science Research Management, 28(3), 169-176.

Yaffe, T., \& Kark, R. (2011). Leading by example: The case of leader OCB. Journal of Applied Psychology, 96(4), 806-826.

Yukl, G. A. (1998). Leadership in organizations (4th ed.). Upper Saddle River: Prentice Hall.

Submit your manuscript to a SpringerOpen ${ }^{\circ}$ journal and benefit from:

- Convenient online submission

- Rigorous peer review

- Open access: articles freely available online

- High visibility within the field

- Retaining the copyright to your article

Submit your next manuscript at $\gg$ springeropen.com 